\title{
Alizarin marking of whitefish, Coregonus lavaretus otoliths during egg incubation
}

\author{
R. ECKMAN N \\ Limnological Institute, University of Konstanz, Konstanz, Germany
}

\begin{abstract}
Alizarin red S from 200 to $5000 \mathrm{mg} \mathrm{L}^{-1}$ was used to mark the otoliths of whitefish embryos Coregonus lavaretus (L.) from 5 days after fertilization until shortly before hatching, to develop a method for evaluating the effect of stocking whitefish. Mark quality depended on developmental stage at the time of immersion. The best results were obtained when the otolith primordia had formed and had started aggregating to form the innermost part of the nucleus. This was verified by in vitro staining of otoliths where the primordia were more intensely stained than the remaining part of the nucleus. The volume ratio eggs to ARS solution, which was 1:10 in all but two treatments, must be observed when comparing fluorochrome concentrations, as mark quality decreased at higher ratios of 1:5 and 1:2. An average mortality rate of 35\% in the most successful treatments was considered tolerable for a mass-marking programme being used under commercial hatchery conditions. This method for marking otoliths of whitefish embryos with ARS during egg incubation is recommended for all cases where marking of larvae is not possible.
\end{abstract}

KEYWORDS: alizarin, Coregonus, otolith marking, otolith primordia, whitefish.

\section{Introduction}

Labelling the otoliths of fish with fluorochrome dyes is a widespread technique used to evaluate stock enhancement programmes (Tsukamoto, Kuwada, Hirokawa, Oya, Sekiya, Fujimoto \& Imaizumi 1989; Yamashita, Nagahora, Yamada \& Kitagawa 1994; Nagata, Nakajima \& Okada 1995; Secor \& Houde 1995; Tsukamoto 1995). When hatchery-reared fish are marked at the larval or juvenile stage, they must be kept in tanks until mass marking by immersion in a fluorochrome solution can be carried out. In a situation where hatchery capacity is limited, so that all or most of the larvae must be released immediately after hatching, a different mass-marking technique is needed that can be applied at an earlier developmental stage, i.e. during egg incubation.

This situation is characteristic of many coregonid hatcheries in Europe where only a minor fraction of eleutheroembryos can be retained and reared in tanks. At Lake Constance, the second largest prealpine lake in Europe, for example, there are five hatcheries with a total incubation jar volume of around $12000 \mathrm{~L}$ (Rösch 1993). With an average hatching success of $70 \%$, approximately 375 million larvae are obtained annu- ally, of which $>95 \%$ are released immediately into the lake. Mass marking of larvae is not feasible under these conditions, but evaluating the effect of stocking is important because of ongoing re-oligotrophication of Lake Constance (Güde, Rossknecht \& Wagner 1998). Fluorochrome labelling of whitefish otoliths during egg incubation was therefore evaluated. It was decided to use alizarin red S (ARS), as hatchery managers declined to use tetracycline (TC) in large-scale tagging programmes.

Earlier studies demonstrated that fish otoliths can be marked with fluorochrome dyes during embryonic development (Dabrowski \& Tsukamoto 1986; Tsukamoto 1988; Blom, Nordeide, Svasand \& Borge 1994; Nagata et al. 1995; Iglesias \& Rodríguez-Ojea 1997), and that this can be carried out as early as at the time of egg fertilization (Ruhlé \& Winecki-Kuehn 1992; Rojas-Beltran, Champigneulle \& Vincent 1995a). In some of these studies, the transport of the fluorochrome dye across the egg envelope was promoted by osmotic shock (Ruhlé \& WineckiKuehn 1992; Rojas-Beltran et al. 1995a; RojasBeltran, Gillet \& Champigneulle 1995b), while in others the eggs were simply immersed in the labelling solution. 
In preliminary trials, some of these published techniques were tested, using ARS instead of the commonly used TC, with little success. Adding ARS at the time of egg fertilization with or without osmotic shock did not mark the otoliths at all (Koechlin 1997), while immersion of eggs at different stages of development yielded inconsistent results, from no mark to easily detectable or even brilliant marks (R. Eckmann, unpublished data). It was suspected that marking success depended on the correct timing of egg immersion. Thus, the purpose of this study was to define the most appropriate phase of whitefish embryonic development for labelling otoliths with ARS.

\section{Materials and methods}

Inshore spawning whitefish (cf. Eckmann \& Roesch 1998) were sampled with bottom-set gill nets during spawning (late November/December). Egg fertilization was carried out on the fishing vessel immediately after lifting the nets. The fertilized eggs were incubated in miniature Zug jars of $300 \mathrm{~mL}$ capacity, which were fed with recirculated tap water. Temperature was maintained at around $4.5^{\circ} \mathrm{C}$, and about $5 \%$ of the system's $250 \mathrm{~L}$ total water volume was exchanged every other day.

Batches of $20 \mathrm{~mL}$ of eggs (corresponding to about 1300 eggs) were used for each treatment. These batches were incubated separately until hatching started. The eggs were then transferred to 14-L aquaria where hatching generally occurred within 3 days. The aquaria were fed with aerated tap water, the temperature of which was gradually increased to $12{ }^{\circ} \mathrm{C}$ within 3 days. Larvae were fed with Artemia nauplii until 3 weeks after hatching. Dead eggs, unhatched embryos, and dead and living larvae were counted to estimate mortality rates.

Experiment 1 was carried out in winter 1999-2000 and comprised the immersion of eggs with and without osmotic shock. All treatments with osmotic shock and one treatment without osmotic shock (at 52 days after fertilization) were replicated. In experiment 2 , carried out in winter 2000-2001, eggs were only immersed without osmotic shock. In this experiment, all treatments except for one $\left(500 \mathrm{mg} \mathrm{L}^{-1}\right.$ ARS at 42 days after fertilization) were replicated. There were two control groups in each experiment.

\section{Immersion with osmotic shock}

Batches of $20 \mathrm{~mL}$ of eggs were added to an Erlenmeyer flask containing $180 \mathrm{~mL}$ of ARS (Aldrich Cat. No. 11 996-2) at a concentration of $5000 \mathrm{mg} \mathrm{L}^{-1}$ in a $5 \%$ solution of $\mathrm{NaCl}$. The $\mathrm{pH}$ was adjusted to around 8 with Tris buffer. The eggs were kept moving by aeration and by repeated swirling of the flask. After $15 \mathrm{~min}$, the eggs were strained into a plastic sieve, thoroughly rinsed with tap water and transferred into a mini Zug jar for further incubation.

\section{Immersion without osmotic shock}

Batches of $20 \mathrm{~mL}$ of eggs were added to mini Zug jars that contained $180 \mathrm{~mL}$ of the ARS solutions at various concentrations (200 and $400 \mathrm{mg} \mathrm{L}^{-1}$ in experiment 1 , 500 and $1000 \mathrm{mg} \mathrm{L}^{-1}$ in experiment 2) The $\mathrm{pH}$ was buffered as described above. The volume ratio between eggs and solution was 1:10, except for two treatments in experiment 2 where the ratio was $1: 5$ and $1: 2$, respectively. The jars were fed with air rather than water to keep the eggs constantly moving. After 24-h immersion, the air supply was shut down, the jars were supplied with water, and the ARS solution was siphoned out of the jars until the upwelling water appeared unstained. The jars were then incorporated into the recirculation system for further incubation.

\section{Mark detection and mark quality}

On the day of hatching and for up to 25 days, samples of larvae were taken and deep-frozen. Sagittae and lapilli were dissected from freshly thawed specimens, cleared from adhering tissue, dried and mounted in Entellan (Merck). Two batches of fish found to have good quality marks were reared for several months to assess mark retention. They were also used to assess the maximum fish size that allows mark detection without the otoliths having to be ground. The otoliths of these fish were embedded in epoxy resin, and they were ground with abrasive paper and polished with aluminium oxide if necessary.

Otoliths were inspected independently by two readers with an epifluorescence microscope (Zeiss filter set no. 487915, $546 \mathrm{~nm}$ excitation wavelength). Mark quality was scored from 0 (no mark visible at $400 \times$ magnification), through 1 (mark not visible at $100 \times$ but visible at $400 \times$ magnification), and 2 (mark easily visible at $100 \times$ magnification), to 3 (mark shining brightly at $100 \times$ magnification). It should be noted that this scoring of mark quality is conservative, as it was specifically designed to facilitate quick and reliable detection of marks in a mass-marking programme. A score of 1, therefore, can be considered as sufficient for successful mark detection, while higher scores indicate that less time is needed for otolith analysis. 


\section{Staining of ground otoliths}

To check the results of the vital staining tests, otoliths of 25-day-old larvae from the control treatments were embedded in epoxy resin and ground to the midplane, so that the otolith nucleus, and particularly the primordia, became exposed at the surface. The otoliths were polished with aluminium oxide and immersed for $60 \mathrm{~min}$ in an ARS solution of $500 \mathrm{mg} \mathrm{L}^{-1}$ at $\mathrm{pH} 8$. After washing and drying, they were covered with a coverslip with Entellan, and the specimens were examined as described above.

\section{Results}

Otoliths of whitefish embryos could be marked with ARS during embryonic development, but mark quality depended on the age of the embryos at the time of immersion and on ARS concentration. The uptake of ARS through the egg chorion was not enhanced by hyperosmotic conditions (Table 1), and this technique was therefore abandoned in the second experiment.

In the first experiment with $400 \mathrm{mg} \mathrm{ARS} \mathrm{L}^{-1}$, immersion of young embryos, i.e. 5 days after fertilization, did not mark the otoliths at all, whereas immersion of advanced embryos, i.e. 38 days after fertilization, provided better mark quality (Table 1). The mark qualities observed with the most advanced embryos, i.e. 52 days after fertilization and older, however, varied considerably between individuals from the same treatment, and even among the four otoliths of one fish: while some otoliths were scored 1 or 1.5 , others had no mark at all. In general, mark quality in the first experiment was inferior to that in the second experiment where higher ARS concentrations were applied.
In the second experiment, the best results were obtained with embryos treated with $1000 \mathrm{mg}$ ARS L ${ }^{-1}$. Mark quality increased significantly with the age of the embryos at the time of immersion (Kruskal-Wallis test, $P<0.05$ ). In embryos treated 28 days after fertilization or later, fluorescent marks were easily visible at $100 \times$ magnification, and mark quality was uniform within and between replicates: all otoliths were scored 1 or better. Higher egg:solution ratios (cf. Table 1) resulted in significantly inferior mark quality (Kruskal-Wallis test, $P<0.05$ ).

Mortality rates varied among treatments and between replicates (Table 2). In the first experiment, mortality rates in the treatments surpassed those in the controls in all but one case. Mortality depended significantly on both the age of the embryos at the time of immersion and on ARS concentration (twoway ANova, $P<0.05$ ). Mortality of eggs treated with osmotic shock did not differ from those treated with $400 \mathrm{mg} \mathrm{ARS} \mathrm{L}^{-1}$ but was significantly higher compared with eggs treated with $200 \mathrm{mg}$ ARS L ${ }^{-1}$ (Tukey test, $P<0.05)$. In the second experiment, mortality rates in the treatments were similar to those in the controls (except for 14 days old embryos treated with $1000 \mathrm{mg} \mathrm{ARS} \mathrm{L}^{-1}$ ). There was no significant relationship between either age of the embryos at the time of immersion or ARS concentration and mortality (twoway ANOvA, $P<0.05$ ). Mortality among the controls $(29.5 \%$ on average) was higher than in the first series of experiments, but it was within a range that is commonly observed in commercial whitefish hatcheries. An average mortality rate of $35 \%$ in the most successful treatments of this experiment, i.e. in embryos immersed 28 days after fertilization or later in $1000 \mathrm{mg}$ ARS L ${ }^{-1}$, was considered tolerable, even for a mass-marking programme.

Table 1. Mark quality (sagittae and lapilli combined) of whitefish larvae immersed in various concentrations of alizarin red S (ARS) at different times of embryonic development

\begin{tabular}{|c|c|c|c|c|c|c|}
\hline \multirow[b]{2}{*}{ Days after fertilization } & \multicolumn{3}{|c|}{ ARS concentration $\left(\mathrm{mg} \mathrm{L}^{-1}\right)$} & \multirow[b]{2}{*}{ Days after fertilization } & \multicolumn{2}{|c|}{ ARS concentration $\left(\mathrm{mg} \mathrm{L}^{-1}\right)$} \\
\hline & 200 & 400 & $5000($ in $5 \% \mathrm{NaCl}$ ) & & 500 & 1000 \\
\hline 5 & $0^{*}$ & $0 *$ & 0 & 14 & 0 & $0.6 \dagger$ \\
\hline 18 & 0 & 0.1 & $0 \dagger$ & 21 & 0.1 & $1.0 \dagger$ \\
\hline 38 & 0.1 & 0.4 & $0.1 \uparrow$ & 28 & 0.3 & $\begin{array}{l}1.3 \dagger \\
0.2 \S \\
0 \uparrow\end{array}$ \\
\hline 52 & 0 & $0.2 \ddagger$ & $0.1 \dagger$ & 35 & 0 & $1.6 \dagger$ \\
\hline 66 & 0 & $0.1 \%$ & $0 \dagger$ & 42 & 0.2 & $2.5 \dagger$ \\
\hline
\end{tabular}

Ten larvae were analysed per treatment $(* 5$ larvae, $\uparrow 20$ larvae). Experiment 1 (left data block): $\ddagger$ mark quality highly variable both between and within individual larvae. Experiment 2 (right data block): the ratio between eggs and ARS solution was 1:10 in all but two treatments (§eggs:solution $=1: 5, \uparrow$ eggs:solution $=1: 2$ ). Hatching occurred 68 days after fertilization in both experiments. 
The best marks were always characterized by intensely stained otolith primordia (Fig. 1a). These spherical structures started to appear at around
28 days after fertilization, and they started to fuse and form the precursor of the otolith nucleus some 4-6 days later. The otolith nucleus had formed by

Table 2. Total mortality (\%) of whitefish embryos, immersed in various concentrations of alizarin red S (ARS) at different times of embryonic development, from the time of immersion marking until three weeks after hatching. Experiment 1: left data block, experiment 2: right data block. Results for replicate treatments are separated by a slash

\begin{tabular}{|c|c|c|c|c|c|c|}
\hline \multirow[b]{2}{*}{ Days after fertilization } & \multicolumn{3}{|c|}{ ARS concentration $\left(\mathrm{mg} \mathrm{L}^{-1}\right)$} & \multirow[b]{2}{*}{ Days after fertilization } & \multicolumn{2}{|c|}{ ARS concentration $\left(\mathrm{mg} \mathrm{L}^{-1}\right)$} \\
\hline & 200 & 400 & $5000($ in $5 \% \mathrm{NaCl})$ & & 500 & 1000 \\
\hline 5 & 23 & 40 & $58 / 78$ & 14 & $20 / 16$ & $57 / 52$ \\
\hline 18 & 28 & 32 & $46 / 46$ & 21 & $28 / 22$ & $26 / 33$ \\
\hline 38 & 19 & 26 & $39 / 36$ & 28 & $25 / 42$ & $26 / 34$ \\
\hline 52 & $7 / 21$ & $14 / 12$ & $18 / 9$ & 35 & $29 / 33$ & $35 / 53$ \\
\hline 66 & 9 & 11 & $17 / 20$ & 42 & 35 & $35 / 27$ \\
\hline Control & \multicolumn{3}{|c|}{$5 / 13$} & Control & \multicolumn{2}{|c|}{$27 / 32$} \\
\hline
\end{tabular}
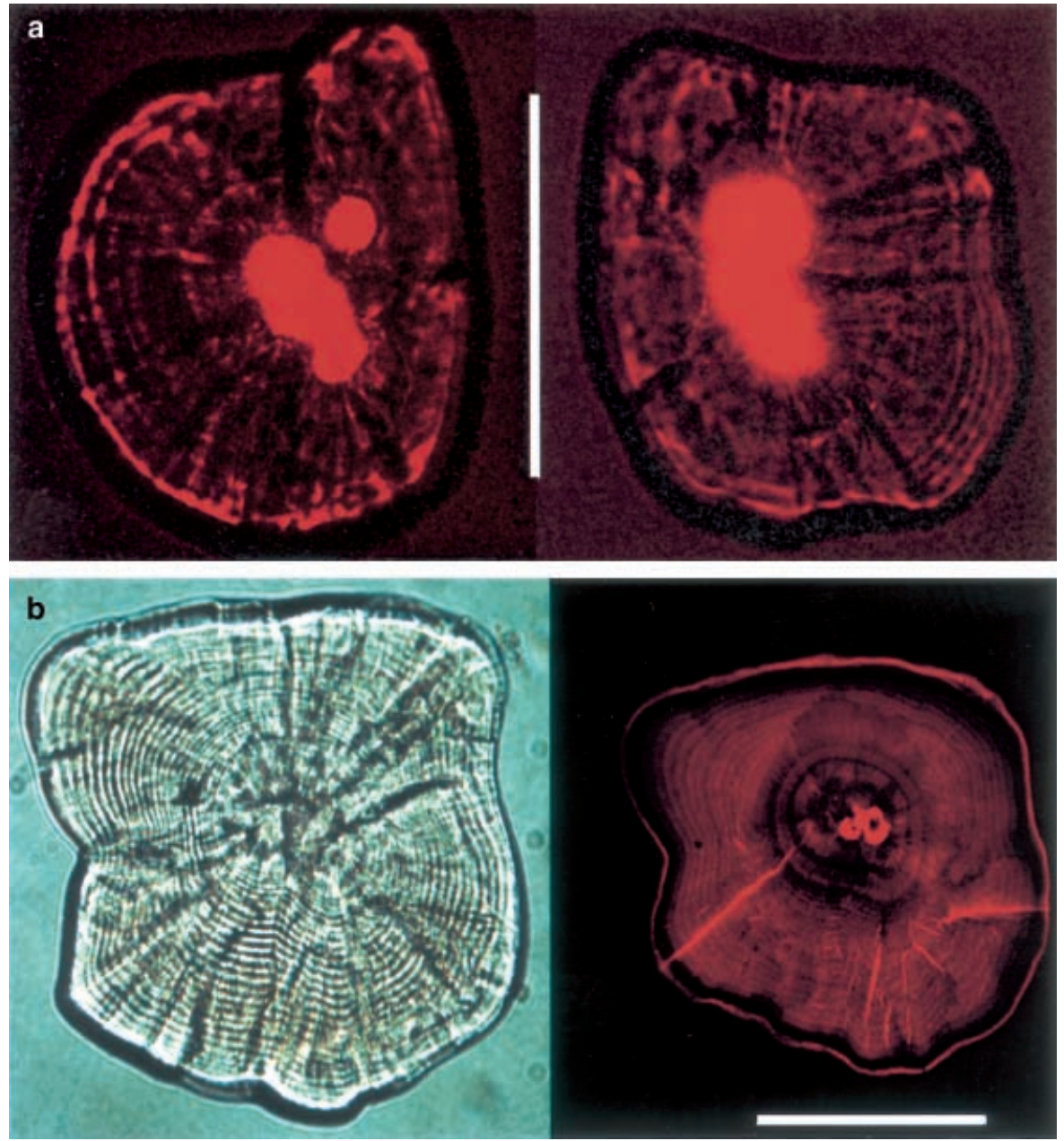

Figure 1. (a) Sagittae from whitefish larvae, which were immersed during egg incubation at the age of 42 days after fertilization in a solution of $1000 \mathrm{mg} \mathrm{L}^{-1}$ alizarin red S for $24 \mathrm{~h}$. The primordia are much more intensely stained than the remaining part of the nucleus. Epifluorescent and transmitted light were applied simultaneously. Scale bar $100 \mu \mathrm{m}$. (b) Ground and polished sagitta from a control group whitefish under transmitted and epifluorescent light. The preparation was immersed in a solution of $500 \mathrm{mg} \mathrm{L}^{-1}$ alizarin red $\mathrm{S}$ for $60 \mathrm{~min}$. The primordia are more intensely stained than other parts of the nucleus and better than daily increments. Scale bar $100 \mu \mathrm{m}$. 
approximately 50 days after fertilization. It consisted of a variable number of primordia, which were surrounded by a layer of lower optical density. This layer continued to grow until the larvae hatched and a hatch-check was formed. Thereafter, daily increments were deposited (cf. Fig. 1b).

When ground and polished otoliths from unmarked larvae were immersed in an ARS solution, the primordia were much more intensely stained than the remaining part of the nucleus (Fig. 1b). This result was further supported by the observation that primordia were less intensely stained as long as they were not exposed at the polished otolith surface but were still covered by the material that surrounds the primordia.

The ARS marks were retained for at least 8 months but the sagittae from fish larger than $45 \mathrm{~mm}$ total length had to be ground to reveal the mark. As whitefish lapilli are smaller than the sagittae, ARS marks could in many cases still be detected in unground lapilli. In the largest fish examined (90-100 $\mathrm{mm}$ total length), marks were still recognizable in the unground lapilli, but their detection was much improved by grinding. With both lapilli and sagittae, it was not necessary to grind the otoliths close to the nucleus to enhance mark detection, so that the risk of overgrinding can easily be avoided.

\section{Discussion}

This study shows that the otolith primordia of coregonids are stained more intensely with ARS than the rest of the otolith nucleus. This observation is particularly relevant for the correct timing of ARS marking of whitefish embryos. At an advanced stage of embryonic development, i.e. when the primordia were already surrounded by material that was less intensely stained than the primordia, mark quality was low. When the eggs were immersed shortly before hatching, a fluorescent mark was deposited which was closely associated with the hatch-check but mark quality was very variable, and larvae started to hatch during immersion, which is not practical for large-scale marking in hatcheries. Thus, the most appropriate time for mass marking of whitefish embryos with ARS is from the appearance of the first primordia until shortly after the primordia have fused to form the innermost part of the otolith nucleus. At an average incubation temperature of $4.5^{\circ} \mathrm{C}$, this occurs after approximately $50-60 \%$ of embryonic development, i.e. 34-42 days after fertilization.

A similar result was reported by Dabrowski \& Tsukamoto (1986) who immersed eyed whitefish eggs in TC, while other authors did not specify which part of the otolith was stained by their particular treatment. Nagata et al. (1995) and Tsukamoto (1995) successfully marked Oncorhynchus masou Brevoort embryos as eyed eggs, by immersion in $200 \mathrm{mg} \mathrm{L}^{-1}$ alizarin complexone (AC) for $24 \mathrm{~h}$. Rojas-Beltran et al. (1995b) marked Salvelinus alpinus (L.) with TC either at the time of fertilization or as eyed eggs, and it appears that the otolith primordia were stained in both treatments. Immersion of embryos shortly before hatching was successful with Scophthalmus maximus (L.) (Iglesias \& Rodríguez-Ojea 1997) and Plecoglossus altivelis Temminck \& Schlegel (Tsukamoto 1988). In the latter study, the AC mark was reported to form a ring, so the outer region of the otolith nucleus was stained but not the primordia.

In the present experiments with ARS, it was not possible to mark the otoliths of whitefish when eggs were immersed at the time of, or shortly after, fertilization. With TC, however, it was possible to mark whitefish (Ruhlé \& Winecki-Kuehn 1992) and Arctic charr (Rojas-Beltran et al. 1995b) otoliths by osmotic incorporation at the time of fertilization. The TC that was taken up during egg hardening must have been deposited within the chorion and then became incorporated into the otolith primordia some weeks later. The ARS, although it forms complexes with calcium in a similar way to $\mathrm{TC}$, apparently has different characteristics, which do not permit its storage within the chorion for a prolonged time. The present study shows that ARS can be transported across the chorion, even without osmotic shock, but ARS must be complexed with calcium and deposited soon thereafter, otherwise it will be leached out of the egg.

Mark quality depended on ARS concentration and on the amount of eggs per unit of ARS solution. Thus, when an ARS solution of $1000 \mathrm{mg} \mathrm{L}^{-1}$ produced good marks, this cannot be considered in absolute terms but must be related to the amount of eggs per unit of solution. The recommended concentration of $1000 \mathrm{mg}$ ARS $\mathrm{L}^{-1}$ will produce good quality marks only when the egg:solution ratio does not increase above 1:10. Some authors do not report precisely the volume ratio of eggs to fluorescent solution or the number of eggs per unit of solution. Consequently, it is difficult to use these results in mass-marking programmes without additional tests.

In an earlier study, Eckmann, Czerkies, Helms \& Kleibs (1998) observed that $\mathrm{pH}$ values of ARS solutions are critical for the survival of coregonid larvae, and recommended adjusting $\mathrm{pH}$ in the range of 7.5-8. Therefore, in the present study $\mathrm{pH}$ of the ARS solutions was always adjusted to around 8 . It is 
conceivable though, that embryos within the chorion are less affected by low $\mathrm{pH}$ values compared with eleutheroembryos, as $\mathrm{pH}$ of the perivitellin fluid is buffered against fluctuations of ambient $\mathrm{pH}$ values (Kuegel \& Peterson 1989). While this problem has not been analysed in detail, it is recommended to use ARS solutions with $\mathrm{pH}$ values around 8 .

Mark retention was verified in this study over at least 8 months, while much longer retention times of fluorescent marks have already been reported (RojasBeltran et al. 1995a; Unkenholz, Brown \& Pope 1997; Eckmann et al. 1998). Thus, it appears safe to assume that mark retention will not be a problem with ARSmarked otolith primordia of whitefish. For reliable detection of marks in larger juveniles, i.e. to avoid false negative results, otoliths should be ground. The preparation of lapilli in addition to the sagittae may help to reduce the need for grinding, because marks are more easily visible in unground lapilli compared with the larger and thicker sagittae.

Marking whitefish larvae with ARS is easier than marking embryos, because a lower ARS concentration is applied during a shorter time and the developmental stage of the fish is not critical (Eckmann et al. 1998). Nevertheless, immersion marking of eggs does provide some advantages for mass marking under hatchery conditions compared with the marking of larvae. (1) There is a time window of about 2 weeks, from the appearance of the first primordia until shortly after the primordia have fused when immersion marking can be carried out. The entire egg stock of a hatchery can thus be treated in small batches within this time window. (2) For the immersion of larvae, a much larger volume of solution is needed compared with when eggs are immersed. In the present study, around 1350 eggs were immersed in $180 \mathrm{~mL}$ of solution, while a density of 1250 larvae $\mathrm{L}^{-1}$ was used by Eckmann et al. (1998). Most published reports on immersion marking of larvae with fluorescent dyes used even lower densities (e.g. Hettler 1984; Blom et al. 1994; Brooks, Heidinger \& Kohler 1994; Nagiec, Czerkies, Goryczko, Witkowski \& Murawska 1995; Iglesias \& Rodríguez-Ojea 1997). Therefore, when eggs instead of larvae are immersed in a fluorescent solution, it is necessary to handle a much smaller volume of solution in accordance with local safety and water protection standards. (3) Handling of eggs, e.g. retrieving them from the fluorescent solution, washing, transferring between jars or tanks, is much easier than with larvae.

In conclusion, a method is now available for marking the otoliths of whitefish embryos with ARS during egg incubation, whereby mortality rates because of the marking process are tolerable. This technique can be used in mass marking operations under hatchery conditions, and it is recommended for all those cases where marking of larvae is not possible.

\section{Acknowledgments}

Many thanks to Myriam Schmid for her invaluable assistance during all laboratory work, especially for her skilful preparation of otoliths. Antje Zahn collected whitefish spawners with gill nets. The members of my group helped with the regular control of egg incubation. Mary Morris corrected the English. This study was supported by Deutsche Forschungsgemeinschaft within the collaborative research center SFB 454, Littoral of Lake Constance.

\section{References}

Blom G., Nordeide J.T., Svasand T. \& Borge A. (1994) Application of two fluorescent chemicals, alizarin complexone and alizarin red $\mathrm{S}$, to mark otoliths of Atlantic cod, Gadus morhua L. Aquaculture \& Fisheries Management 25, 229-243.

Brooks R.C., Heidinger R.C. \& Kohler C.C. (1994) Massmarking otoliths of larval and juvenile walleyes by immersion in oxytetracycline, calcein, or calcein blue. North American Journal of Fisheries Management 14, 143-150.

Dabrowski K. \& Tsukamoto K. (1986) Tetracycline tagging in coregonid embryos and larvae. Journal of Fish Biology 29, 691-698.

Eckmann R., Czerkies P., Helms C. \& Kleibs K. (1998) Evaluating the effectiveness of stocking vendace (Coregonus albula (L.)) eleutheroembryos by alizarin marking of otoliths. Archiv für Hydrobiologie, Special Issues Advances in Limnology 50, 457-463.

Eckmann R. \& Roesch R. (1998) Lake Constance fisheries and fish ecology. Archiv für Hydrobiologie, Special Issues Advances in Limnology 53, 285-301.

Güde H., Rossknecht H. \& Wagner G. (1998) Anthropogenic impacts on the trophic state of Lake Constance during the 20th century. Archiv für Hydrobiologie, Special Issues Advances in Limnology 53, 85-108.

Hettler W. (1984) Marking otoliths by immersion of marine fish larvae in tetracycline. Transactions of the American Fisheries Society 113, 370-373.

Iglesias J. \& Rodríguez-Ojea G. (1997) The use of alizarin complexone for immersion marking of the otoliths of embryos and larvae of the turbot, Scophthalmus maximus (L.): dosage and treatment time. Fisheries Management and Ecology 4, 405-417.

Koechlin V. (1997) Fluorochrome Markierung von Fischembryonen, Diploma Thesis. Albert-Ludwigs-Universität, Freiburg, 63 pp (in German). 
Kuegel B. \& Peterson R.H. (1989) Perivitelline fluid $\mathrm{pH}$ of rainbow trout Oncorhynchus mykiss eggs in relation to ambient pH. Canadian Journal of Fisheries and Aquatic Sciences 46, 2070-2073.

Nagata M., Nakajima M. \& Okada H. (1995) Growth differences between wild and domestic juvenile masu salmon, Oncorhynchus masou, as determined by otolith marking of domestic fish at the eyed-egg stage. In: D.H. Secor, J.M Dean \& S.E. Campana (eds) Recent Developments in Fish Otolith Research. Columbia: University of South Carolina Press, pp. 445-454.

Nagiec M., Czerkies P., Goryczko K., Witkowski A. \& Murawska E. (1995) Mass-marking of grayling, Thymallus thymallus (L.), larvae by fluorochrome tagging of otoliths. Fisheries Management and Ecology 2, 185-195.

Rojas-Beltran R., Champigneulle A. \& Vincent G. (1995a) Mass-marking of bone tissue of Coregonus lavaretus L. and its potential application to monitoring the spatio-temporal distribution of larvae, fry and juveniles of lacustrine fishes. Hydrobiologia 301, 399-407.

Rojas-Beltran R., Gillet C. \& Champigneulle A. (1995b) Immersion mass-marking of otoliths and bone tissue of embryos, yolk-sac fry and fingerlings of Arctic charr Salvelinus alpinus (L.). Nordic Journal of Freshwater Research 71, 411-418.

Rösch R. (1993) Fischbrutanstalten - früher und heute. In: T. Kindle (ed.) Bodenseefischerei. Sigmaringen: Jan Thorbecke Verlag, pp. 124-130 (In German).

Ruhlé C. \& Winecki-Kuehn C. (1992) Tetracycline marking of coregonids at the time of egg fertilization. Aquatic Sciences 54, 165-175.
Secor D.H. \& Houde E.D. (1995) Larval mark-release experiments: potential for research on dynamics and recruitment in fish-stocks. In: D.H. Secor, J.M. Dean \& S.E. Campana (eds) Recent Developments in Fish Otolith Research. Columbia: University of South Carolina Press, pp. 423-444.

Tsukamoto K. (1988) Otolith tagging of ayu embryo with fluorescent substances. Nippon Suisan Gakkaishi 54, 1289 1295.

Tsukamoto K. (1995) Use of otolith-tagging in a stock enhancement program for masu salmon (Oncorhynchus masou) in the Kaji River, Japan. In: D.H. Secor, J.M. Dean \& S.E. Campana (eds) Recent Developments in Fish Otolith Research. Columbia: University of South Carolina Press, pp. 403-422.

Tsukamoto K., Kuwada H., Hirokawa J., Oya M., Sekiya S., Fujimoto H. \& Imaizumi, K. (1989) Size-dependent mortality of red sea bream, Pagrus major, juveniles released with fluorescent otolith-tags in News Bay, Japan. Journal of Fish Biology 35, 59-69.

Unkenholz E.G., Brown M.L. \& Pope K.L. (1997) Oxytetracycline marking efficacy for yellow perch fingerlings and temporal assays of tissue residues. Progressive Fish Culturist 59, 280-284.

Yamashita Y., Nagahora S., Yamada H. \& Kitagawa, D. (1994) Effects of release size on survival and growth of Japanese flounder Paralichthys olivaceus in coastal waters off Iwate Prefecture, northeastern Japan. Marine Ecology Progress Series 105, 269-276. 